Dr Vlado Đurković, Vojna akademija

Rezime:

Osnovni merni elementi u sistemu upravljanja projektila su žiroskopi, visinomeri i prenosnici. Žiroskopi su uređaji koji otkrivaju odstupanje projektila od željenih uslova leta i smatraju se osnovnim mernim elementom u raketnom sistemu upravljanja. Visinomeri i prenosnici koriste se u sekundarnim ili pomoćnim servospregama kontrolnog sistema upravljanja.

Cilj rada jeste upoznavanje sa osnovnim principima na kojima počiva upotreba žiroskopa, kao i analiziranje žiroskopskih efekata. Takođe, razmatra se $i$ krutost žiroskopa $i$ žiroskopska precesija.

Ključne reči: žiroskop, merni elementi, sistem upravljanja, žiroskopski efekti.

\title{
GYROSKOP BASED MEASURING ELEMENTS SYSTEM DRIVE
}

\section{Summary:}

This paper focuses on some aspects of development and modernization of contemporary multirole combat aircraft. In compliance with a large number of innovations developed in every generation of multirole combat aircraft as well as comprehensive modernization of existing types, the main essential and interactive aspects are emphasized here.

Key words: Multirole combat aircraft, construction, performance, avionics, power group, fire power.

\section{Razvoj žiroskopa}

Drvi žiroskop (grčka reč gyros znači gledati, a reč skopein obrtanje rotacija) izradio je francuski naučnik Foucault 1852. godine. Predstavlja jedan od najvažnijih inercijalnih senzora koji meri uglovnu brzinu ili male uglovne pomeraje oko referentne ose. Kada meri uglovnu brzinu zove se brzinski žiroskop (rate gyroscope), a kada meri male uglovne pomeraje (zaokrete) - integrirajući žiroskop (rate integrating gyroscope). U engleskoj literaturi umesto reči gyroscope koristi se kraća reč gyro. 
Senzori su uređaji ili elementi koji imaju sposobnost da otkriju ili izmere neki parametar ili veličinu koja karakteriše let rakete [9]. Služe za merenje određenih parametara leta rakete i davanje dopunskih upravljačkih signala autopilotu.

Svaki senzor sastoji se od dva osnovna dela: merača i davača. Merač meri vrednost parametara ili veličine, a davač izmerenu vrednost merača pretvara u oblik signala informacije pogodnom za korišćenje u autopilotu.

Senzori koji se koriste kao elementi autopilota vođenih raketa mogu se svrstati u dve grupe:

- senzori za merenje parametara linearnog kretanja centra mase rakete, kao što su: akcelerometri linearnog ubrzanja, brzinomeri, visinomeri, termometri i dr.;

- senzori za merenje ugaonog kretanja rakete oko centra mase, u koje spadaju: merači uglova propinjanja, skretanja i valjanja, merači ugaonih brzina,merači ugaonih ubrzanja i dr.

Kao senzori autopilota najčešće se primenjuju žiroskopi i akcelerometri.

\section{Opšte karakteristike žiroskopa}

Pod žiroskopom se podrazumeva svako kruto telo koje relativno brzo rotira oko svoje ose materijalne simetrije, pri čemu ta osa ima jednu nepomičnu tačku i menja pravac u prostoru (čigra, sl. 1). Ugaona brzina okretanja tela mnogo puta je veća od ugaone brzine kojom se okreće osa tela. Prema tome, žiroskop u opštem slučaju vrši sferno kretanje $[3,4,5]$.

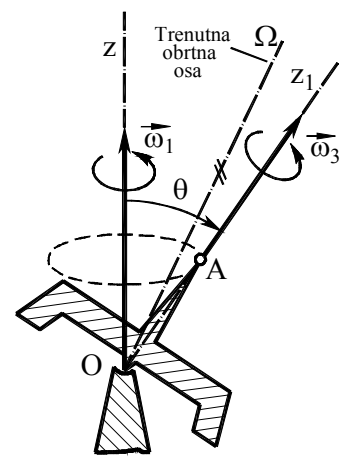

Slika 1 - Žiroskop

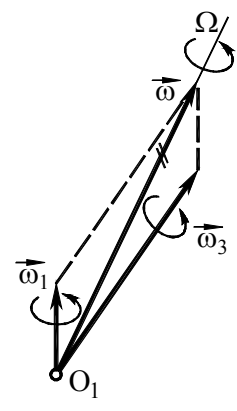

Slika 2 - Žiroskop u kardanovom ramu

Drugi primer je žiroskop u kardanovom ramu (sl. 2). Kod njega teški disk, pored sopstvene rotacije ugaonom brzinom $\omega_{3}=\dot{\varphi}$, oko ose $O z$, ima i precesiono kretanje oko ose $O z_{1}$, ugaonom brzinom $\omega_{1}=\dot{\psi}$, kao i nutaciono 
kretanje ugaonom brzinom $\omega_{2}=\dot{\theta}$, oko čvorne ose ON. Tako disk može da vrši tri međusobno nezavisne rotacije oko osa koje se presecaju u centru masa $O$, koji ostaje stalno nepokretan.

Spreči li se obrtanje diska, npr. oko ose $O z_{1}$, od žiroskopa sa tri stepena slobode kretanja dolazi se do žiroskopa sa dva stepena slobode.

Slučaj sfernog kretanja tela može se tačno proučiti primenom zakona o promeni momenta količine kretanja. Međutim, korišćenjem tog zakona dolazi se do diferencijalnih jednačina kretanja, koje se u veoma malom i ograničenom broju slučajeva mogu rešiti u jednom zatvorenom obliku.

Zbog svega toga biće korišćena tzv. približna teorija žiroskopskih pojava, koja daje dovoljno tačne rezultate za većinu problema koji se javljaju u praksi.

Moment količine kretanja za tačku O (sl.3a, $[3,4,5])$ jeste:

$\vec{L}_{O}=\overline{O A}, \vec{L}_{O}=J_{z} \vec{\omega}$

Pretpostavka je da žiroskop vrši složeno kretanje. U slučaju da je ugaona brzina nutacije $\vec{\omega}_{2} \approx 0$, a ugaona brzina sopstvene rotacije $\vec{\omega}_{3}$ mnogo veća od ugaone brzine precesije $\vec{\omega}_{1}$, tada je (sl. $\left.3 b\right)$ :

$\vec{\omega}_{3}>\vec{\omega}_{1}$

$\vec{\omega}_{a}=\vec{\omega}=\vec{\omega}_{1}+\vec{\omega}_{2}+\vec{\omega}_{3}=\vec{\omega}_{1}+\vec{\omega}_{3}$,

$\vec{\omega} \approx \vec{\omega}_{3}$

$\mathrm{Na}$ osnovu prethodnih izraza moment količine kretanja (sl. 3c) jeste:

$\vec{L}_{z} \approx J_{z} \vec{\omega}$
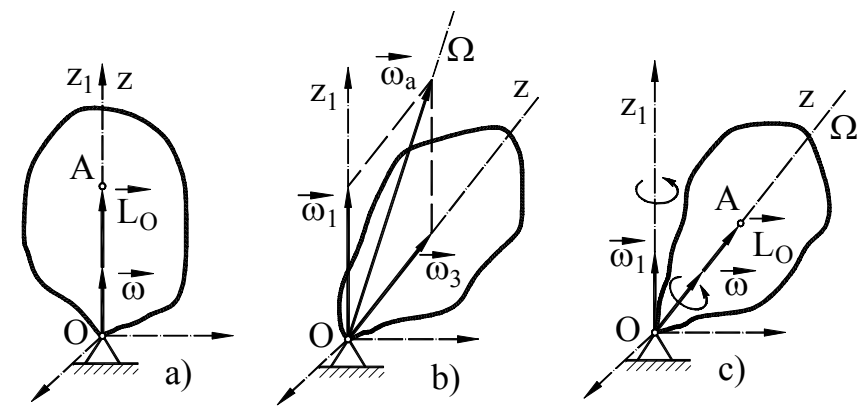

Slika 3 - Telo pri sfernom kretanju

Izrazi (4) i (5) praktično predstavljaju i osnovu približne teorije žiroskopa (sl. 3c), koja se može iskazati na sledeći način: ako se žiroskop veoma brzo obrće oko svoje ose, tada je moment količine kretanja žiroskopa definisan izrazom (5) i usmeren uzduž ose materijalne simetrije žiroskopa. 
Svojstva žiroskopa poseduju nebeska tela, artiljerijski projektili, rotori turbina, različite instalacije na brodovima, elise aviona, itd.

$U$ savremenoj tehnici žiroskop jeste osnovni element moćnih žiroskopskih uređaja ili pribora, koji se koriste za automatsko upravljanje kretanja aviona, projektila, brodova, torpeda, i slično. Koriste se u navigaciji za stabiliziranje kretanja brodova po uzburkanom moru, za promenu ugaonih i translatornih brzina projektila, a i u mnoge druge specijalne svrhe.

Brojni su uređaji koji su primenjeni u vojne svrhe, čija konstrukcija počiva na principima žiroskopa $[2,6,9,10]$. Tehničke primene žiroskopa u današnje vreme toliko su mnogostruke i raznovrsne da je nastala potreba da se iz opšte teorije žiroskopa izdvoji posebna disciplina, koja se naziva „primenjena teorija žiroskopa“.

\section{Karakteristike žiroskopa sa tri stepena slobode kretanja}

Žiroskop sa tri stepena slobode kretanja (sl. 4) ima veoma važnu karakteristiku - protivi se promeni pravca svoje ose u prostoru $[3,4,5]$. Da bi se ona proučila biće opisan jedan tzv. astatički žiroskop, tj. žiroskop čije se težište poklapa sa nepomičnom tačkom (sl. 1, 4, 5).

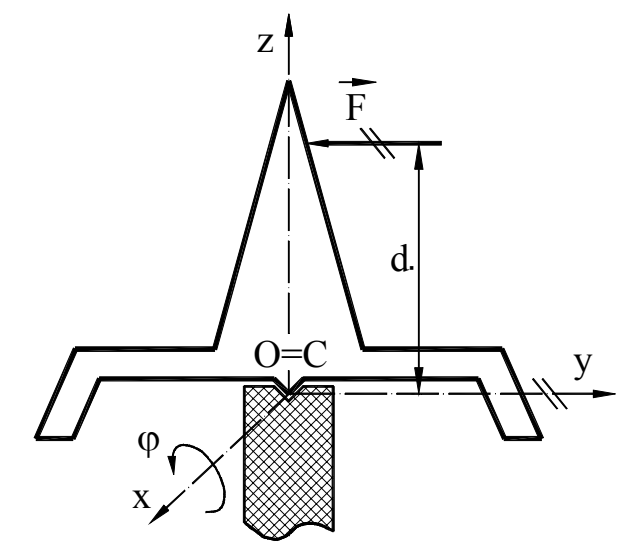

Slika 4 - Žiroskop koji ne rotira pod dejstvom sile tada je:

Ako žiroskop ne rotira oko svoje ose, i ako na njega deluje sila (sl. 4),

$J_{x}\left(d^{2} \varphi / d t^{2}\right)=F \cdot d$

$J_{x} \omega=F \cdot d \cdot t+J_{x} \omega_{0} \Rightarrow \varphi=\frac{F \cdot d}{2 J_{x}} \cdot t^{2}+\omega_{0} t+\varphi_{0}$ 
Vidi se da će u ovom slučaju, pri konstantnoj sili, žiroskop vršiti ravnomerno ubrzanu rotaciju oko ose koja je upravna na ravan dejstva sile.

Kada prestane da deluje sila, žiroskop će imati neku ugaonu brzinu i dalje će nastaviti da se kreće tom brzinom oko ose Ox.

$\omega_{\varphi 1}=\frac{F \cdot d}{J_{x}} \cdot t_{1}$

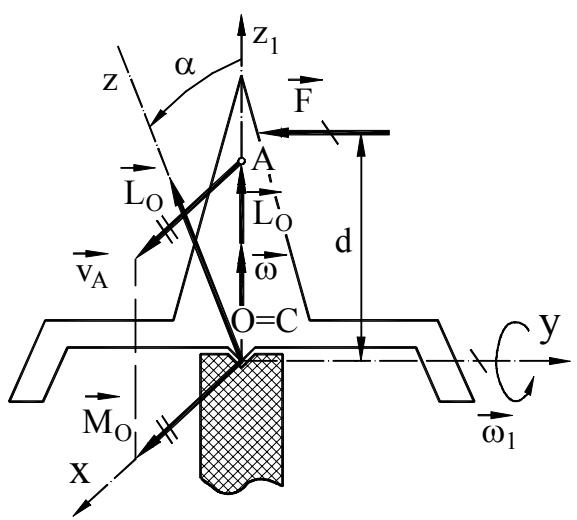

Slika 5 - Žiroskop sa tri stepena slobode kretanja koji brzo rotira pod dejstvom sile

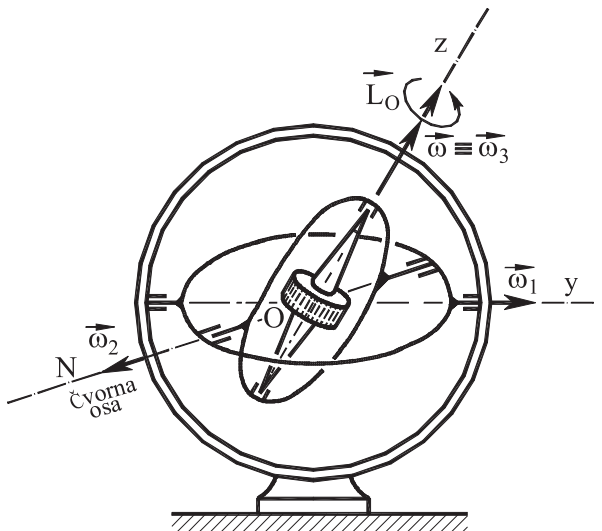

Slika 6 - Žiroskop sa tri stepena slobode kretanja

Razmatra se dejstvo sile na isti ovakav žiroskop, ali koji se veoma brzo okreće oko svoje ose materijalne simetrije ugaonom brzinom $\vec{\omega}$ (sl. 5). Tada je:

$$
\vec{L}=J_{z} \vec{\omega}
$$

Primenjujući zakon o promeni momenta količine kretanja dobija se da je:

$$
\begin{aligned}
& \frac{d \vec{L}_{O}}{d t}=\vec{M}_{O}^{\vec{F}_{R}^{s}} \\
& \frac{d \vec{L}_{O}}{d t}=\frac{d \overrightarrow{O A}}{d t}=\vec{v}_{A}
\end{aligned}
$$

gde je $\vec{v}_{A}$ brzina vrha vektora $\vec{L}_{O}$. Upoređujući (10) i (11) vidi se da je:

$$
\vec{v}_{A}=\vec{M}_{O}^{\bar{F}_{R}^{s}}
$$

Može se zaključiti da se pod dejstvom sile $\vec{F}$ tačka $A$, pa prema tome i osa $O z$, ne kreće u ravni $y O z$, nego u ravni $x O z$, što znači da se osa ovog žiroskopa, pod dejstvom sile, pomera u ravni koja je normalna na ravan dejstva sile. 
Onog trenutka kada prestane da deluje sila, spoljašnji moment će postati jednak nuli, a time i brzina tačke $A$. To znači da će tog trenutka prestati da se kreće (ostaće u tom položaju) i osa žiroskopa.

Osa žiroskopa se obrće oko ose y ugaonom brzinom $\omega_{1}$, pri čemu je:

$v_{A}=\overline{O A} \cdot \omega_{1}=F \cdot d$

$\omega_{1}=F \cdot d / \overline{O A}$

$\omega_{1}=\frac{F \cdot d}{J_{z} \omega}$

Ovim izrazom (15) definisana je ugaona brzina precesije, tj. ona ugaona brzina kojom osa žiroskopa rotira oko ose koja je paralelna dejstvu sile.

\section{Regularna precesija}

Ako se pretpostavi da žiroskop nije uravnotežen, odnosno da se centar inercije žiroskopa ne poklapa sa nepomičnom tačkom (sl. 7), kao i da osa simetrije zaklapa sa stalnom osom $z_{1}$ ugao $\theta$ i da se žiroskop brzo obrće oko ose simetrije $[3,4,5]$, na osnovu zakona o promeni momenta količine kretanja sledi da je brzina vrha $(\mathrm{A})$ vektora $\vec{L}_{O}$ :

$\vec{v}_{A}=\frac{d \vec{L}_{O}}{d t}=\vec{M}_{O}^{\vec{F}_{R}^{s}}=\overrightarrow{O C} \times \vec{G}$

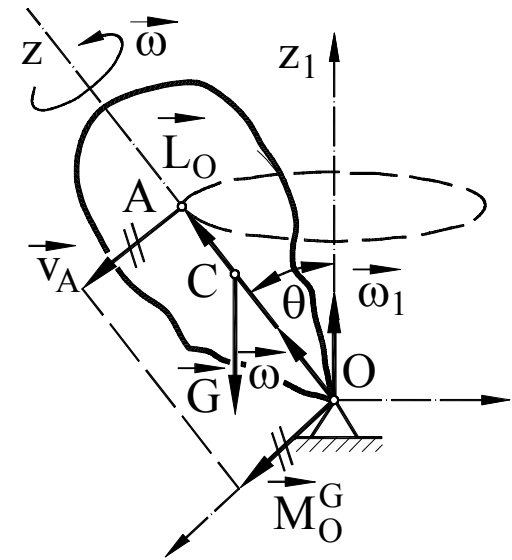

Slika 7 - Neuravnoteženi žiroskop koji rotira pod dejstvom sile teže 
Sledi da će se sopstvena osa obrtati oko stalne ose $z_{1}$ nekom ugaonom brzinom $\vec{\omega}_{1}$. Prema tome, a na osnovu sl. 7, biće:

$\left|\vec{M}_{O}^{\vec{F}_{R}^{s}}\right|=G \cdot \overline{O C} \cdot \sin \theta$

$\left|\frac{d \vec{L}_{O}}{d t}\right|=\left|\vec{v}_{A}\right|=\omega_{1} L_{O} \sin \theta$

Iz (16) i (17) sledi da je ugaona brzina rotacije ose simetrije oko stalne ose $z_{1}$ pod delovanjem sile teže na neuravnoteženi žiroskop, koji se brzo obrće, tj. ugaona brzina regularne precesije:

$\omega_{1}=\frac{G \cdot \overline{O C}}{L_{O}} \Rightarrow \omega_{1}=\frac{G \cdot \overline{O C}}{J_{z} \omega}$

\section{Žiroskop sa dva stepena slobode, žiroskopski moment}

Žiroskop sa dva stepena može da se obrće u ramu, sopstvenom ugaonom brzinom $\vec{\omega}$, a ram može da se obrće u ležištima $A$ i $B$, ugaonom brzinom $\vec{\omega}_{1}$, kao što je prikazano na sl. 8.

Primenjujući na žiroskop sa dva stepena slobode (znajući da je $\vec{\omega}>>\vec{\omega}_{1}$ ), zakon o promeni momenta količine kretanja: $\frac{d \vec{L}_{O}}{d t}=\vec{M}_{O}^{\vec{F}_{R}^{s}}$, te uzimajući u obzir da je $\vec{L}_{O}=J_{z} \vec{\omega}$, može se pisati:

$$
\begin{aligned}
& \left|\frac{d \vec{L}_{O}}{d t}\right|=\left|\vec{v}_{K}\right|=L_{O} \omega_{1}=J_{z} \omega \cdot \omega_{1}=\left|\vec{M}_{O}^{\vec{F}_{R}^{s}}\right|=\left|\vec{M}_{O}^{\vec{S}}\right| \\
& \sum_{i=1}^{n} \vec{M}_{O}^{\vec{F}_{i}^{s}}=\vec{M}_{O}^{\vec{F}_{R}^{s}}=\vec{M}_{O}^{\vec{G}}+\vec{M}_{O}^{\vec{F}_{A}^{s t}}+\vec{M}_{O}^{\vec{F}_{B}^{s t}}+\vec{M}_{O}^{\vec{F}_{A}^{d}}+\vec{M}_{O}^{\vec{F}_{B}^{d}}
\end{aligned}
$$

$U$ poslednjem izrazu sila težine $\mathrm{G}$ i statičke reakcije ne čine moment za tu tačku. 


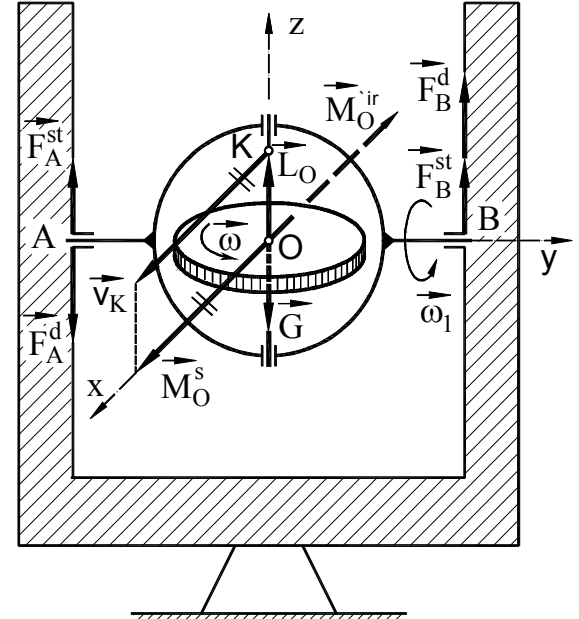

Slika 8 - Neuravnoteženi žiroskop koji rotira pod dejstvom sile teže

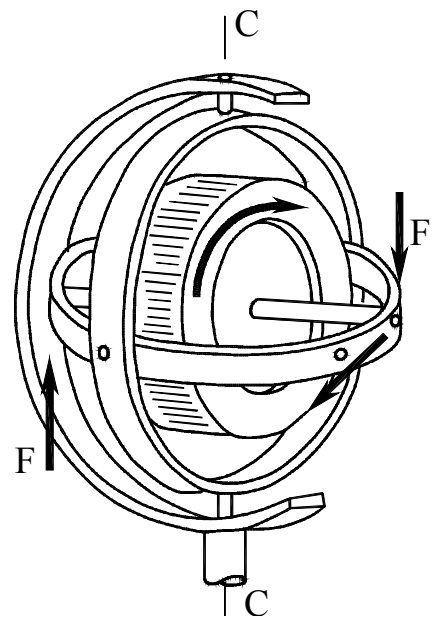

Slika 9 - Žiroskopski moment (precesiranje)

Iz zakona o kretanju centra inercije: $m \vec{a}_{C}=\sum_{i=1}^{n} \vec{F}_{i}^{s}=\vec{F}_{R}^{s}=0$,

$\vec{G}+\vec{F}_{A}^{s t}+\vec{F}_{B}^{s t}+\vec{F}_{A}^{d}+\vec{F}_{B}^{d}=0$,

što govori da se u osloncima $A$ i $B$ javljaju dodatne dinamičke reakcije. Takođe, iz poslednjeg izraza sledi da sile $\vec{F}_{A}^{d}$ i $\vec{F}_{B}^{d}$ čine spreg sila, tj. sledi da je:

$\vec{F}_{A}^{d}=-\vec{F}_{B}^{d}$,

dok je glavni moment sila jednak:

$$
\begin{aligned}
& \left|\vec{M}_{O}^{\vec{F}_{R}^{s}}\right|=F_{A}^{d} \cdot \overline{A O}+F_{B}^{d} \cdot \overline{B O}=F_{A}^{d} \cdot \overline{A B}=F_{B}^{d} \cdot \overline{A B} \\
& F_{A}^{d}=F_{B}^{d}=\frac{J_{z} \omega \omega_{1}}{\overline{A B}}
\end{aligned}
$$

Ukupne reakcije u tačkama $A$ i $B$ osovine žiroskopa određuju se vektorskim zbirom statičkih i dinamičkih reakcija ležišta $A$ i $B$, odnosno:

$$
\begin{aligned}
& F_{A_{\min }}=F_{B_{\text {min }}}=\left|F_{A}^{d}-\frac{m g}{2}\right|=\left|F_{A}^{s t}-F_{A}^{d}\right|=\left|\frac{G}{2}-\frac{J_{z} \omega \omega_{1}}{\overline{A B}}\right| \\
& F_{A_{\max }}=F_{B_{\max }}=\left|F_{A}^{d}+\frac{m g}{2}\right|=\left|F_{A}^{s t}+F_{A}^{d}\right|=\left|\frac{G}{2}+\frac{J_{z} \omega \omega_{1}}{\overline{A B}}\right|
\end{aligned}
$$


Na osnovu zakona akcije i reakcije [3,5] žiroskop dejstvuje na ležišta A i B silama $\vec{F}_{A}^{\text {ir. }}$ i $\vec{F}_{B}^{\text {'ir. }}$ koje su istog pravca i intenziteta (sl. 8), a suprotnog smera od dinamičkih reakcija $\vec{F}_{A}^{d}$ i $\vec{F}_{B}^{d}$, pa i te sile obrazuju spreg koji se

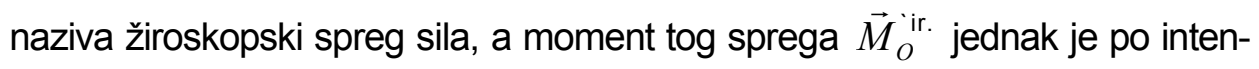
zitetu i pravcu momentu $\vec{M}_{O}^{\vec{F}_{R}^{s}}$ samo je suprotnog smera od njega, odnosno:

$$
\vec{M}^{\text {ir. }}=-\vec{M}_{O}^{\vec{F}_{R}^{s}}
$$

i naziva se žiroskopski moment. Nastajanje žiroskopskog momenta naziva se žiroskopski efekt. Žiroskopski moment, odnosno žiroskopski efekt javlja se uvek kada se menja pravac obrtne ose žiroskopa i ako se ta promena brže vrši (veće $\vec{\omega}_{1}$ ) žiroskopski pritisci u ležištima tada mogu višestruko da nadmaše vrednost statičkih pritisaka i zbog toga se uticaj žiroskopskih pritisaka mora uzeti u obzir prilikom proračuna ležišta.

Ukoliko bi na žiroskop sa dva stepena slobode delovala sila paralelna osi $x$, tada on (odnosno njegova osa rotacije) ne bi imao rotaciju oko ose $x$, što bi se desilo kod žiroskopa sa tri stepena slobode. Ta rotacija ne bi postojala za žiroskop sa tri stepena slobode, zbog postojanja ležišta $A$ i $B$. Prema tome, žiroskop sa dva stepena slobode nema karakteristiku da se pri delovanju neke sile suprotstavlja promeni pravca ose rotacije, nema osobinu protivdejstva, već se usled promene njenog pravca javlja žiroskopski efekt.

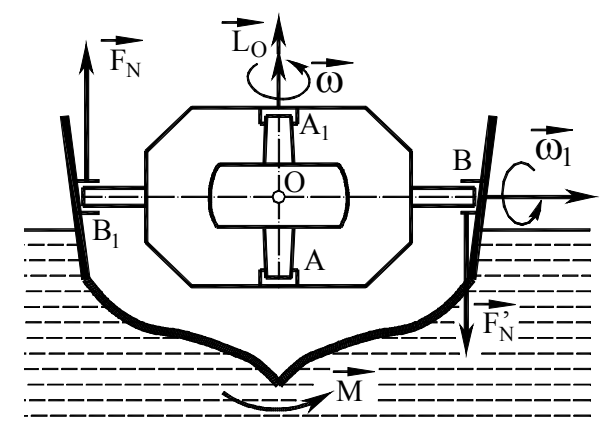

Slika 10 - Primer žiroskopskog stabilizatora direktnog dejstva na ljuljanje broda

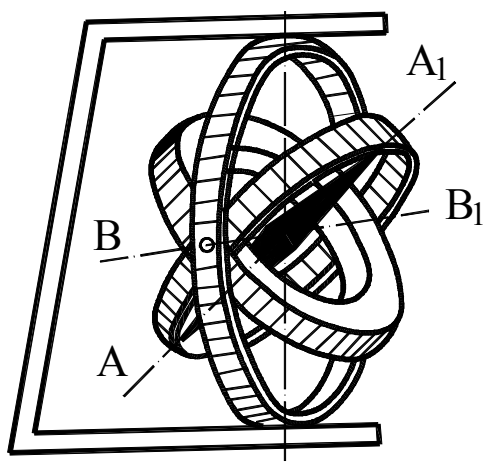

Slika 11 - Primer žiroskopa sa dva stepena u stabilizaciji vozila

Zbog svojih osobina žiroskopi se koriste u tehnici na onim mestima [7] gde treba obezbediti stabilnost nekog kretanja (sl. 10, 11). Na primer, šinsko vozilo (žiroskop sa dva stepena slobode, sl. 11), sa stalnom ugaonom brzinom sopstvene rotacije $\vec{\omega}_{3} \approx \vec{\omega}$, oko ose $A A_{1}$. U slučaju da se vagon nagne 
ulevo, dovoljno je ramu saopštiti ugaonu brzinu $\vec{\omega}_{1}$ oko ose $B B_{1}$, pa će se usled presecionog kretanja pojaviti žiroskopski moment, koji vraća vozilo $u$ ravnotežni položaj. Isto je i kada bi se vozilo nagnulo na drugu stranu, samo bi ugaona brzina prinudne precesije $\vec{\omega}_{1}$ trebalo da ima suprotan smer [4]. Danas postoje raznovrsni uređaji za automatsko obrtanje rama.

\section{Krutost žiroskopa}

Krutost ili žiroskopska inercija je svojstvo žiroskopa da se odupre ma kojoj sili koja nastoji da mu otkloni rotor iz ravni rotacije [8, 9]. Na krutost (inerciju) žiroskopa utiču sledeći faktori: masa rotora, momenat inercije i broj obrtaja rotora.

Krutost žiroskopa može se povećati povećanjem mase rotora, rasporedom mase više prema spoljnoj ivici rotora i povećanjem broja obrtaja. Povećanjem mase rotora povećava se i težina, što je nepovoljno, a povećanje broja obrtaja ima svoju granicu i zavisi od izdržljivosti (veka) ležaja. rotora:

Krutost žiroskopa izražava se preko momenta količine kretanja ( $L$ )

$$
L=J \cdot \omega
$$

gde je: $J$-moment inercije rotora žiroskopa; $\omega$-ugaona brzina rotora žiroskopa.

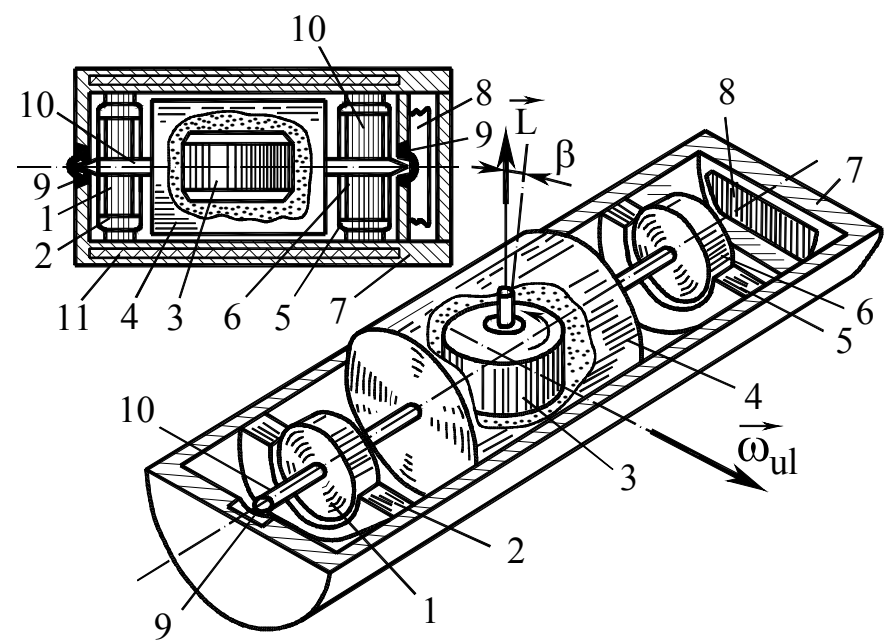

Slika 12 - Plivajući žiroskop

1 - rotor davača momenta; 2 - stator davača momenta; 3 - žiromotor;

4 - plovak; 5 - stator davača signala; 6 - rotor davača signala; 7 - telo;

8 - kompenzator; 9 - ležaj; 10 - osovina plovka; 11 - spirala grejača 
Da bi se povećao broj obrtaja rotora, odnosno smanjilo opterećenje ležaja, primenjuju se tzv. plivajući žiroskopi (sl. 12). Kod ovih žiroskopa rotor je smešten u hermetički zatvorenu kutiju, koja je ispunjena tečnošću, pri čemu je tečnost iste gustine kao i plovak, tako da praktično nema sile trenja. Međutim, i ovi žiroskopi imaju svoje nedostatke. U toku rada zagreva se tečnost (menja se gustina), pa se narušava potpuno vešanje plovka i pojavljuje se pritisak na ležajima. Da bi se to sprečilo ugrađuju se uređaji za regulaciju temperature, što je složeno i dalje povećava masu.

Pored plivajućih žiroskopa u primeni su žiroskopi sa vazdušnim vešanjem (ležajima) [1, 2]. Kod ovih žiroskopa se umesto tečnosti primenjuje vazduh pod pritiskom, koji stvara vazdušni jastuk između osovine rotora i ležajeva i tako smanjuje trenje. Zahvaljujući primeni ove vrste ležaja trenje se svodi na jedan toliko zanemarljiv stepen da se može smatrati komponentom nulte veličine. Vazdušni ležaji rade na istom principu kao vakuumski uređaji za čišćenje u kojima jedna velika gumena lopta lebdi na koničnoj vazdušnoj struji. Osnovni princip žiroskopa sa vazdušnim ležajima prikazan je na sl. 13.

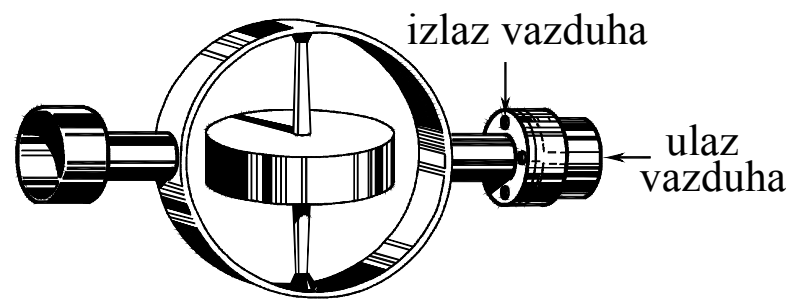

Slika 13 - Žiroskop sa vazdušnim ležajima

lako dosta usavršeni, vazdušni ležaji dali su jedan neželjeni autorotacioni ili turbinski momenat prouzrokovan nesimetrijom vazdušnog toka i Fukoovim strujama. Usavršavanje konstrukcije ležaja bez sumnje će eliminisati ove nedostatke. Početni uspesi u ovom pravcu pokazali su da su u žirostabilizaciji moguća stostruka poboljšanja.

\section{Žiroskopska precesija}

Važna karakteristika žiroskopa jeste žiroskopska precesija, a postoje dve vrste: stvarna (pobuđena) i prividna žiroskopska precesija.

Stvarna precesija. Stvarna žiroskopska precesija (sl. 5) omogućava da rotor bude pomeren ne u pravcu sile koja na njega deluje, nego za $90^{\circ}$ od pravca sile, i to u pravcu obrtanja rotora [2]. Ako jedna sila deluje u tački A, i to nadole, ona je preneta kroz stožer B na ram $\mathrm{C}$, takođe kao sila koja deluje nadole. Ova sila kreće se $90^{\circ}$ u pravcu rotacije i prouzrokuje kretanje tačke D nadole, uz istovremeno kretanje (precesiju) tačke $E$ (sl. 14). 


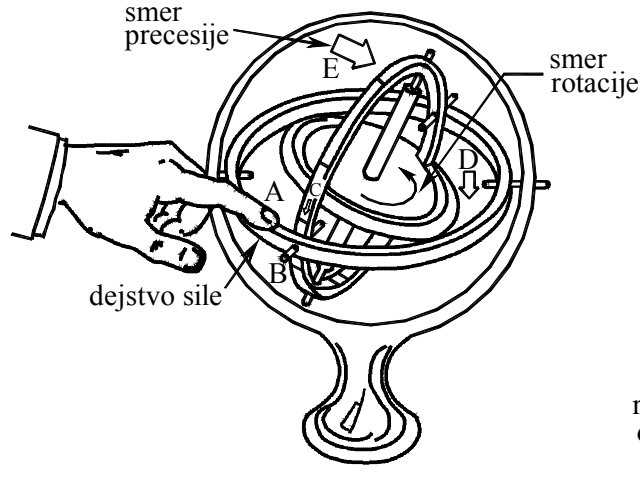

Slika 14 - Određivanje pravca precesije žiroskopa

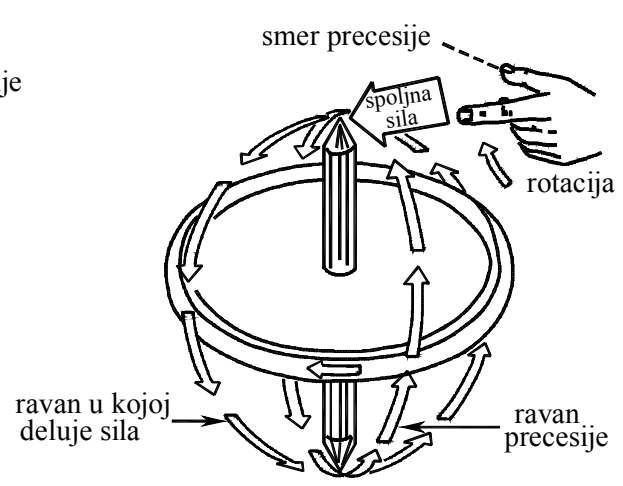

Slika 15 - Precesija žiroskopa

Lak način da se zapamti pravac precesije žiroskopa, kada na njega deluje spoljna sila, jeste da se zna „pravilo ruke“, kao što je pokazano na slici 15. Prste leve ili desne ruke valja postaviti u pravcu obrtanja žiroskopa $\mathrm{i}$ ispružiti kažiprst u pravcu sile koja deluje na žiroskop. Palac će tada da bude okrenut u pravcu precesije. Ovo pravilo poznato je i pod nazivom tzv. teorema Žukovskog (sl. 16).

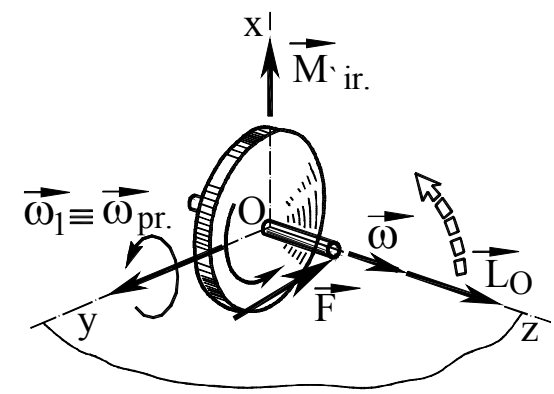

Slika 16 - Pravilo precesije

$\vec{F}$ - spoljna sila; $\vec{\omega}_{1}=\vec{\omega}_{p r}$ - ugaona brzina precesije; $\vec{\omega} \approx \vec{\omega}_{3}-$ vektor ugaone brzine rotora; $\vec{L}_{\mathrm{O}}$ - moment količine kretanja; $\vec{M}_{\text {`ir. }}$ - moment spoljne sile

Dakle, pod prividnom precesijom podrazumeva se karakteristika žiroskopa da se njegov rotor pod dejstvom spoljne sile pomeri u ravni koja je upravna na ravan dejstva sile [9]. Smer precesije zavisi od toga u koju stranu se okreće rotor i kako je usmeren moment spoljnih sila. Pravilo precesije glasi: pri dejstvu spoljnih sila vektor ugaone brzine rotora $(\vec{\omega})$ nastoji da se poklopi sa vektorom momenta spoljnih sila ( $\vec{M}_{{ }_{\text {ir. }}}$ ) i to najkraćim putem (sl. 16). 
Očigledno je, iz prethodnog objašnjenja žiroskopske precesije, da sila koja deluje na žiroskop u centru njegove gravitacije neće učiniti da se osa rotora nagne i da žiroskop time izmeni prethodno uspostavljeni položaj. Dakle, neće doći do pojave precesije. Prema tome, žiroskop koji rotira može biti pokretan u ma kojem pravcu, isto kao i žiroskop u miru pod uslovom da njegove osovine ostanu paralelne sa svojim prvobitnim položajem u prostoru. Prema tome, žiroskop obezbeđuje stabilnost samo u odnosu na naginjanje sopstvene ose obrtanja, Takođe, žiroskop koji rotira može da bude upotrebijen da obezbedi stabilizaciju jedino u ravnima koje sadrže njegove ose obrtanja. Za potpunu stabilizaciju u svakom avionu potrebna su dva žiroskopa, koja imaju, jedan u odnosu na drugog, ose obrtanja pod pravim uglom. Zbog toga su potrebna oba žiroskopa - i vertikalni i horizontalni - da bi se dobila potpuna stabilizacija i da bi se uspostavile potrebne referentne linije u odnosu na koje se može meriti odstupanje.

Prividna precesija. Prividna precesija nastaje zbog okretanja Zemlje oko svoje ose [7,8,9]. Kao što se na sl. 17, 18, 19, 20 i 21 vidi, zbog rotacije Zemlje posmatraču izgleda kao da se osa rotora naginje. Tako, na primer, ako jedan rotor žiroskopa ima horizontalnu osu usmerenu u pravcu istokzapad u odnosu na Zemlju, tek posle 3 časa osa rotora biće nagnuta u odnosu na pravac istok-zapad za $45^{\circ}$, posle 6 časova za $90^{\circ}$, itd. (sl. 21).

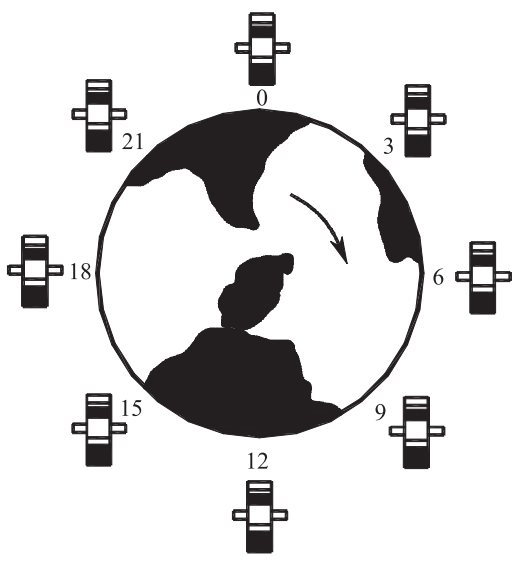

Slika 17 - Položaj žiroskopa u prostoru oko zemlje - prividna precesija žiroskopa

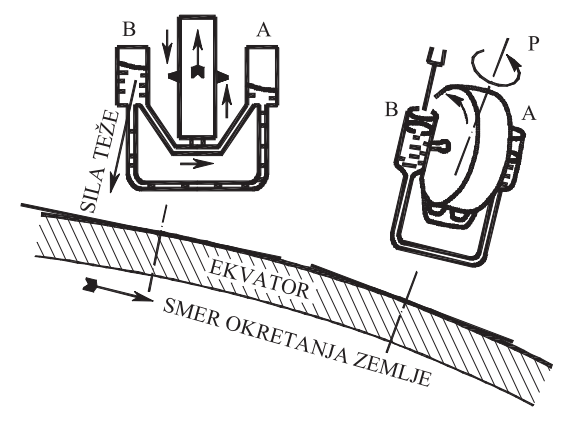

Slika 18 - Postavljanje ose žiroskopa u meridijan zbog delovanja sile teže

Zemlja se okreće u pravcu strelice (u pravcu kazaljke na satu sl. $17,18,19)$ ugaonom brzinom od jednog obrtaja na 24 časa (tačnije 23 časa, 56 minuta i 44 sekunde). Ugaona brzina okretanja Zemlje iznosi $\omega=7,20 \cdot 10^{-}$ ${ }^{5} \mathrm{~s}^{-1}$ ili 15 step./h. Za posmatrače u prostoru izgledaće da osa obrtanja održava svoj položaj u pravcu istoka. Ali, za posmatrače na Zemlji izgledaće da se osa obrtanja postepeno naginje (sl 19). 


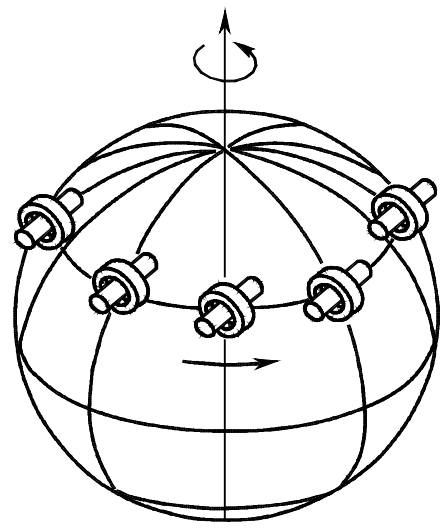

Slika 19 - Ponašanje slobodnog žiroskopa tokom rotacije Zemlje

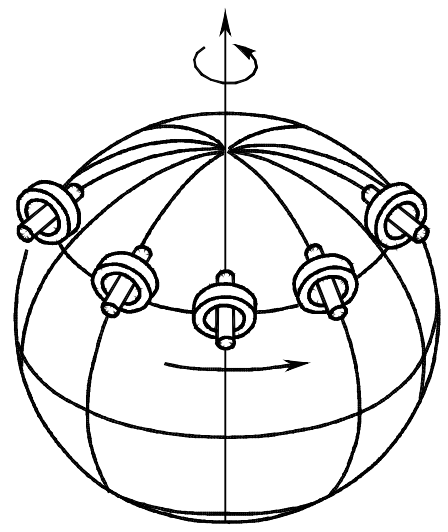

Slika 20 - Ponašanje žiroskopa podešenog prema Zemlji
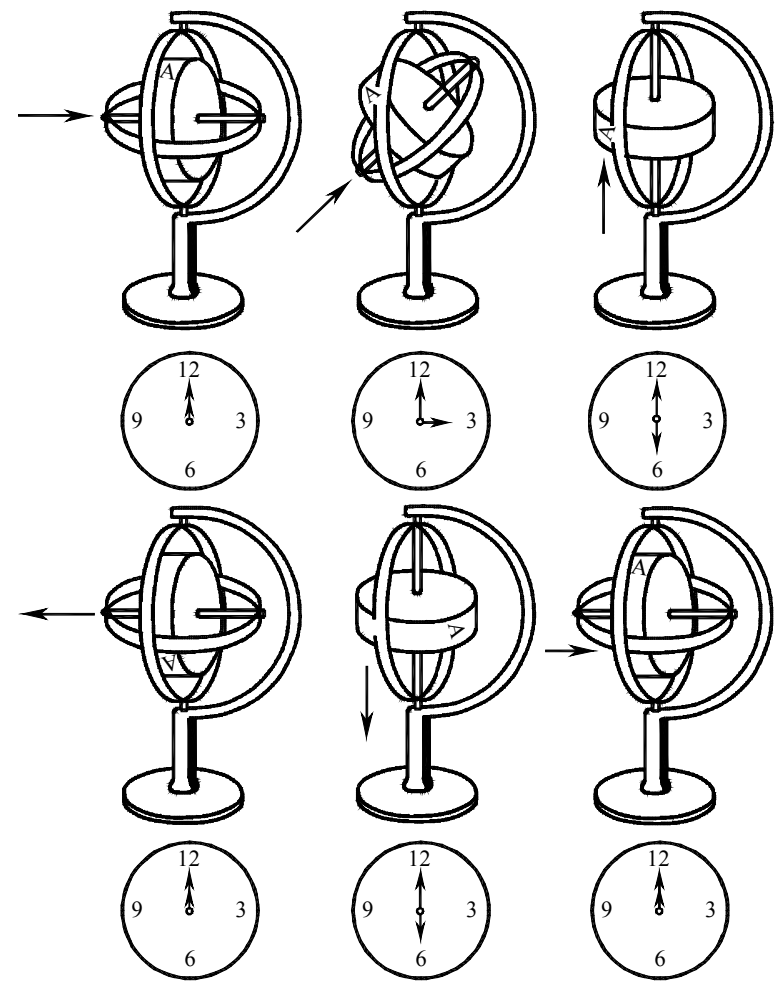

Slika 21 - Prividna precesija

Ovaj fenomen stvara iluziju da se žiroskop obrće i da u toku svaka 24 časa izvrši jedan obrtaj. Međutim, žiroskop zadržava svoj položaj u prostoru, a zemlja se obrće oko njega. Ovo okretanje u odnosu na žiroskop zove 
se prividna žiroskopska precesija. Najveća prividna precesija je na ekvatoru, prema polovima se smanjuje, a na samim polovima je ravna nuli.

Prividna precesija čini žiroskop nepodesnim kao referencu pri upotrebi u dužim periodima, ukoliko nije primenjena neka vrsta mehanizma za ukrućivanje ili za kompenzaciju koji bi održavao žiroskop u stalnom odnosu prema površini zemlje. U relativno kratkim periodima žiroskop, ipak, može da bude upotrebljen za uspostavljanje zadovoljavajuće reference, i to bez upotrebe mehanizma za ukrućivanje ili kompenzaciju.

\section{Pomeranje nule}

Žiroskop nije uvek usmeren u pravcu u kojem bi teorijski trebalo da bude (sl. 19, 20). Ove greške u žiroskopu prouzrokovane su slučajnim netačnostima sistema. Rezultujuće promene položaja ose obrtanja zovu se drift. Postoje tri glavna izvora drifta [2,6]:

- neizbalansiranost. Kada radi na brzinama ili temperaturama različitim od predviđenih žiroskop često postaje dinamički neizbalansiran. Određena neizbalansiranost postoji u svakom žiroskopu, jer proces proizvodnje ne daje potpunu simetriju sastavnih elemenata;

- trenje u ležajima. Usled trenja u ležajima ramova gubi se energija i pozicija ramova postaje netačna. Trenje u ležajima obrtne osovine prouzrokuje drift jedino ako trenje nije simetrično, dok podjednako trenje u ležaju prouzrokuje samo promenu brzine obrtanja;

- inercija ramova. Kada ram rotira gubi se energija usled inercije ramova. Što je veća masa rama veći je i drift prouzrokovan ovom pojavom. Izgleda nemoguće da se sasvim eliminiše drift u žiroskopu. Ipak, u poslednjim godinama veliki uspesi postignuti su u smanjivanju veličine drifta.

\section{Određivanje brzine}

Kada se u projektilu nalazi žiroskop sa dva rama, od kojih je jedan ograničen (fiksiran) oprugama, ili nekim sličnim sredstvom, on saopštava silu sredstvu za ograničenje (oprugama) koja je proporcionalna ugaonoj brzini kretanja projektila u jednoj ravni. Merenjem date sile na ograničivačima direktno se dobija indikacija brzine skretanja.

\section{Brzinski žiroskop}

Prvi brzinski žiroskop izradio je francuski naučnik Leon Foucault 1852. godine, ali u to vreme nije našao primenu. Ispitujući rotaciju Zemlje Foucault je izradio kardanski rotor koji se okreće velikom brzinom. Uočio je da pravac njegovog ugaonog momenta ostaje nepromenjen u prostoru [6]. 


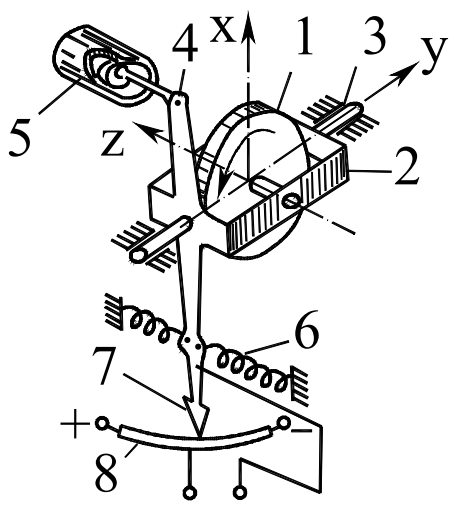

Slika 22 - Brzinski žiroskop

1 - rotor; 2 - ram; 3 - oslonac; 4 - poluga amortizera; 5 - amortizer; 6 - opruga; 7 - klizač potenciometra; 8 - potenciometarski davač

Pojavom prvih aviona ponovo se radi na usavršavanju žiroskopa, tako da su svoju primenu našli već početkom 1930. godine u određivanju kursa. Bili su to prvi mehanički pneumatski žiroskopi. Naime, rotor se prvo obrtao pneumatskim, a zatim električnim putem (elektromotor), tako da se taj žiroskop zvao elektro-mehanički žiroskop. Zbog negativnog uticaja trenja u ležajevima i velike potrošnje struje kod mehaničkih i elektromehaničkih žiroskopa, u periodu 1950-1970. godine, koristi se tačniji „plivajući” elektromehanički (floated gyro), kod kojeg se kardan i rotor uranjaju u tečnost. Podmornice i strateški avioni koriste još tačnije elektromehaničke žiroskope sa elektrostatičkim ležajevima (ESG-electrostatically suspended gyro).

Brzinski žiroskop služi za merenje ugaone brzine rakete oko bilo koje ose (uzdužne - brzina valjanja, poprečne - brzina propinjanja, i vertikalne - brzina skretanja) tokom leta (sl. 26).

Za merenje ugaonih brzina primenjuju se dvostepeni žiroskopi [8]. Na slici 22 prikazano je merenje ugaone brzine oko vertikalne ose $x-x$ (brzina skretanja rakete). Unutrašnji ram dvostepenog žiroskopa oslanja se na telo rakete.

Pri okretanju rakete oko ose $x-x$ sa određenom ugaonom brzinom $\left(\omega_{x}\right)$ pojavljuje se žiroskopski moment ( $M_{\text {`ir. }}$ ), koji teži da ram (2) sa rotorom (1) zaokrene oko ose $x-x$. Pod dejstvom ovog momenta nastaje precesija žiroskopa - okreće se ram (2) zajedno sa rotorom (1) oko ose $y-y$. Precesiji žiroskopa suprotastavlja se opruga (6), koja je vezana preko poluge (4) na ram (2). Pri sabijanju opruge stvara se moment koji je proporcionalan precesionom dejstvu rama oko ose $y-y$. To znači da je ugao za koji se zaokrene ram žiroskopa proporcionalan ugaonoj brzini rakete. Pri zaokretanju rama zaokretaće se i kazaljka klizača (7), koja svojim vrhom skida napon sa potenciometra (8). 
Polarnost i veličina skinutog napona odgovara smeru i veličini ugaone brzine rakete.

Brzinski žiroskop, koji je upotrebijen u prvoj primeni, sličan je slobodnom žiroskopu po tome što ima veliki žiroskopski moment, jer mu se rotor obrće. Ipak, razlikuje se po tome što je slobodan da rotira samo oko jedne osovine i osetljiv je samo na ugaonu brzinu kretanja. Naime, ugaono kretanje njegovog kućišta, pri prekoračenju određene brzine, izaziva promenu položaja ose obrtanja žiroskopa u odnosu na prostor. Takve promene javljaju se za $90^{\circ}$ u pravcu rotacije od ugaonog momenta koji deluje i u pravcu kretanja. Slika 23 prikazuje dejstvo brzinskog žiroskopa kada je upotrebljen u sistemu projektila [2].

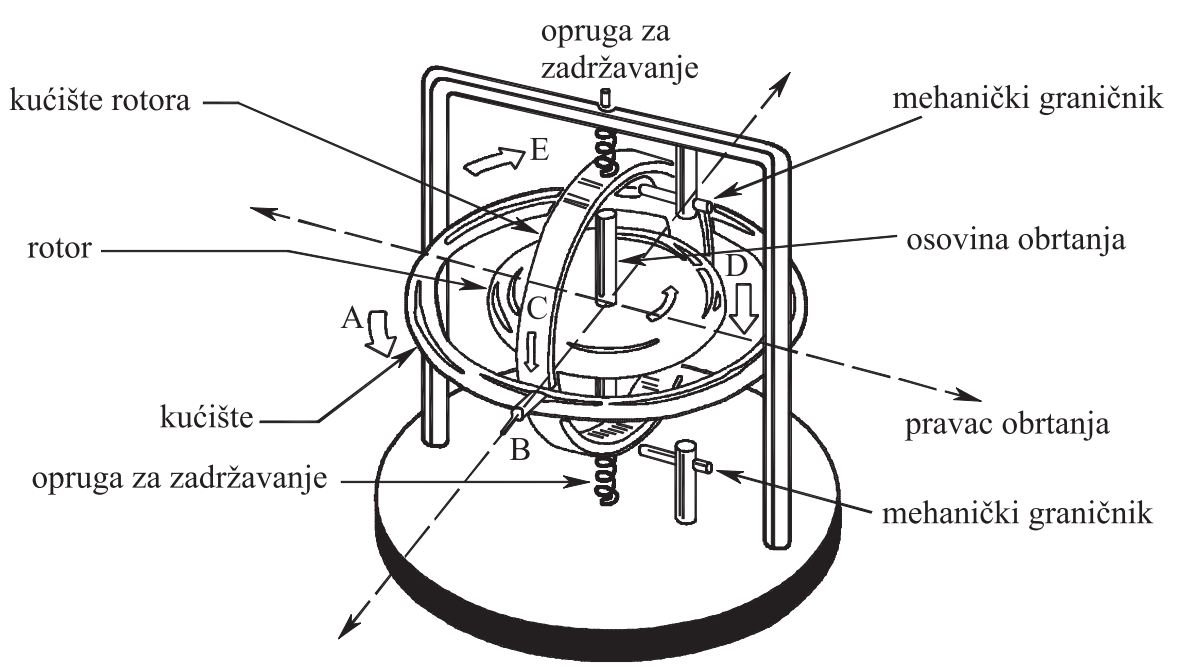

Slika 23 - Dejstvo brzinskog žiroskopa

Ugaona sila koja deluje na kućište u tački $A$ prenosi se preko stožera $B$ kao sila koja deluje nadole na ram $C$. Ova sila kreće se za $90^{\circ}$ u pravcu obrtanja i prouzrokuje moment koji deluje nadole u $D$ sa potonjom precesijom u E. Ćim ugaona brzina koja je saopštena kućištu prestane, opruge za ograničavanje vraćaju žiroskop u njegov neutralni položaj.

Primena brzinskih žiroskopa kod projektila visokih performansi mora da bude od znatne koristi. Tri brzinska žiroskopa kombinovana sa kompaktnim elektronskim integratorima daju odličan izvor reference skretanja gde vođenje nije funkcija žiroskopskog sistema. Kontrolni sistemi ovoga tipa su u opsegu između žiroskopskih i elektronskih dostignuća.

Pneumonični brzinski žiroskop pojavio se u novije vreme, a nema ni rotor ni ramove, odnosno ni jedan pokretan deo. Princip njegovog rada zasniva se na korišćenju efekta vrtložnog strujanja gasa pod veoma malim pritiskom $(0,1-0,5$ bara) u komori specijalnog oblika [9]. 
Vrtložno strujanje gasa može biti prinudno ili slobodno. Kod prinudnog vrtloženja sve čestice gasa imaju istu ugaonu brzinu, pa je brzina $(v)$ direktno proporcionalna poluprečniku rastojanja posmatranog elementarnog dela vrtloga od centra vrtloženja, odnosno:

$v=k \cdot r$

Povećanjem poluprečnika tangencijalna brzina se povećava linearno, a isto je i sa centrifugalnom silom.

U slučaju slobodnog vrtloga brzina( $v)$ menja se obrnuto proporcionalno poluprečniku $(r)$ prema formuli:

$v=\frac{k}{r}$

pa se centrifugalna sila smanjuje povećanjem poluprečnika.

Kod pneumoničnog brzinskog žiroskopa iskorišćen je princip prinudnog vrtložnog strujanja.

Princip rada pneumoničnog brzinskog žiroskopa može se objasniti pomoću sl. 24.
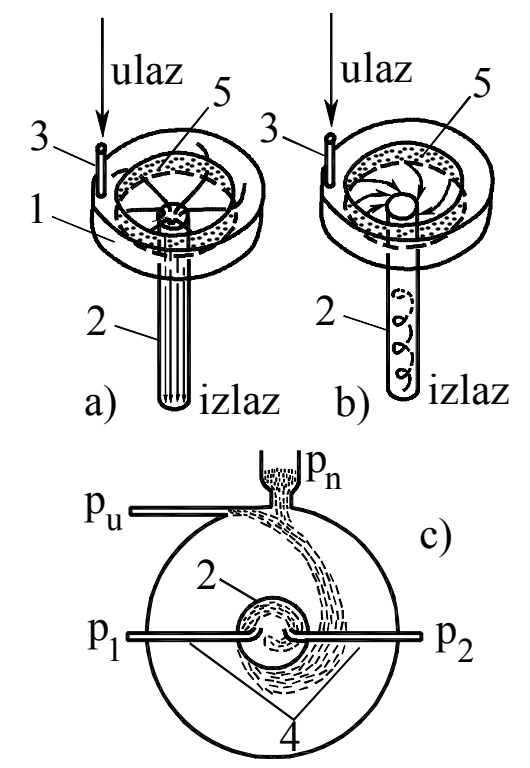

Slika 24 - Šema i princip rada pneumoničnog brzinskog žiroskopa

a) - pri odsustvu obrtanja žiroskopa; b) - kada postoji ugaona brzina obrtanja;

c) - šema davača diferencijalnog pritiska pneumoničnog žiroskopa; $p_{\mathrm{n}}$ - pritisak napajanja; $p_{\mathrm{u}}$ - pritisak adekvatnog upravljačkog mlaza; $p_{1}, p_{2}-$ pritisci na krajevima pito cevi; I - komora; 2 - odvodna cev; 3 - dovodna cev; 4 - pito cevi; 5 - porozna pregrada 
Žiroskop se sastoji od komore prstenastog oblika (1), odvodne cevi (2), dovodne cevi (3) i dve pito cevi (4).

U komori (1) postavljena je jedna prstenasta pregrada (5) od poroznog materijala. Kroz dovodnu cev gas se uvodi u komoru.

Kada raketa nema ugaonu brzinu (sl. 24.a) gas struji radijalno kroz poroznu pregradu (5) i linearno kroz odvodnu cev (2).

Kada se raketa ugaono kreće (sl. 24.c) u komori (1) i odvodnoj cevi pojavljuje se vrtložno kretanje gasa, pri čemu je njegova tangencijalna brzina proporcionalna ugaonoj brzini rakete, tj. žiroskopa, jer se kretanje žiroskopa prenosi na strujnice gasa u komori posredstvom trenja u graničnom sloju.

Na kraju odvodne cevi meri se diferencijalni pritisak pomoću dve pito cevi: $\Delta p=p_{1}-p_{2}$ gde je:

$p_{1}$ - pritisak u jednoj pito cevi;

$p_{2}$ - pritisak u drugoj pito cevi.

Kada raketa (žiroskop) ne vrši ugaono kretanje diferencijalni pritisak je $\Delta p=0$.

Kada raketa ima ugaonu brzinu pojavljuje se diferencijalni pritisak $(\Delta p)$ proporcionalan ugaonoj brzini. Smer pritiska određuje smer ugaone brzine. Diferencijalni pritisak $(\Delta p)$ predstavlja senzorski parametar ugaone brzine, koji se pomoću fluidnih pojačavača pojačava i odvodi dalje kao brzinski signal autopilota.

Pneumonični žiroskopi su veoma pouzdani u radu, jer nemaju ni jedan pokretan deo. Vek trajanja im je veoma dug i jeftini su. Preciznost pneumoničnih žiroskopa je veća od klasičnih rotorskih žiroskopa za 10 puta, pa i znatno više.

Ziroskop za merenje linearne brzine rakete predstavlja neuravnoteženi žiroskop čiji je centar mase smešten van jedne od osa vešanja.

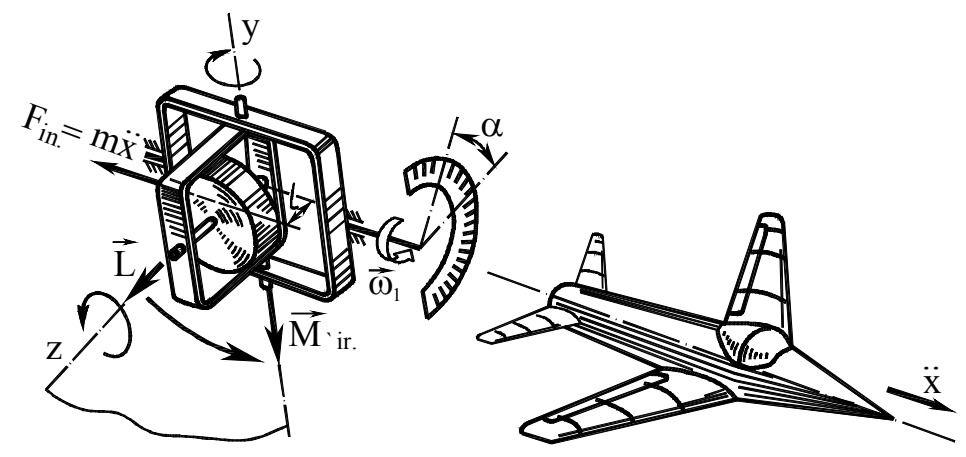

Slika 25 - Šema i princip rada žiroskopa za merenje linearne brzine

$\ddot{x}$ - ubrzanje rakete; $F_{\text {in }}=m \ddot{x}$ - sila inercije žiroskopa; $M_{\text {`ir. }}$ - moment neuravnoteženog žiroskopa; $\alpha$ - ugao zaokreta žiroskopa 
Radi objašnjenja principa rada takvog žiroskopa razmatra se jednostavan primer. Pretpostavlja se da se žiroskop nalazi u raketi koja leti horizontalno [6, 8]. Osovina spoljnjeg rama žiroskopa (služi kao osa osetljivosti) postavljena je paralelno u odnosu na uzdužnu osu rakete, kao što je prikazano na sl. 25. Moment količine kretanja je upravan na osu osetljivosti.

Kada raketa menja brzinu na žiroskop deluje sila inercije $\left(F_{i n}\right)$ koja je jednaka proizvodu njegove mase $\left(m_{\ddot{z} i r .}\right)$ i ubrzanja rakete $(\ddot{x})$, tj:

$F_{i n}=m_{\check{z i r} .} \cdot \ddot{x}$

Ako bi žiroskop bio uravnotežen uticaj sile $\left(F_{i n}\right)$ odrazio bi se samo u vidu dopunskog pritiska na ležaje. Ali, žiroskop je neuravnotežen i zato sila inercije $\left(F_{i n}\right)$ na kraku $(I)$ stvara moment $(M)$ u odnosu na osu unutrašnjeg rama:

$M_{\text {zir. }}=F_{\text {in }} \cdot l=m_{\text {zir. }} \cdot \ddot{x} \cdot l$

Ovaj moment izaziva precesiju žiroskopa oko ose spoljašnjeg rama brzinom precesije:

$\omega_{p r}=\omega_{1}=\frac{M_{z i r} .}{L}=\frac{m_{\ddot{z i r} .} \cdot \ddot{x} \cdot l}{J \cdot \omega}$

Vrednosti $\left(m_{\text {.ir. }}\right),(I),(J)$ i $(\omega)$ su konstante i mogu se obeležiti sa $K_{i}=m_{\text {żir. }} \cdot l / L$. Tu veličinu nazivamo konstantom instrumenta. Tako dobijamo da je $\omega_{p r}=K_{i} \cdot \ddot{x}$, tj. brzina precesije žiroskopa je proporcionalna ubrzanju rakete. U skladu $s$ tim ugao zaokreta rotora žiroskopa oko ose spoljašnjeg rada proporcionalan je brzini rakete:

$\alpha=K_{i} \cdot \dot{x}=K_{i} \cdot v$

Dakle, pri kretanju rakete sa ubrzanjem koje je normalno na osetljivu osu žiroskopa brzina precesije žiroskopa je proporcionalna ubrzanju rakete, a ugao zaokreta brzini rakete.

Poznato je da linearna brzina predstavlja integral linearnog ubrzanja. Zato se može reći da je ugao $(\alpha)$ proporcionalan linearnoj brzini $(\dot{x})$, a brzina proporcionalna integralu ubrzanja $(\ddot{x})$. Ovakav žiroskop naziva se žirogenerator ubrzanja. 


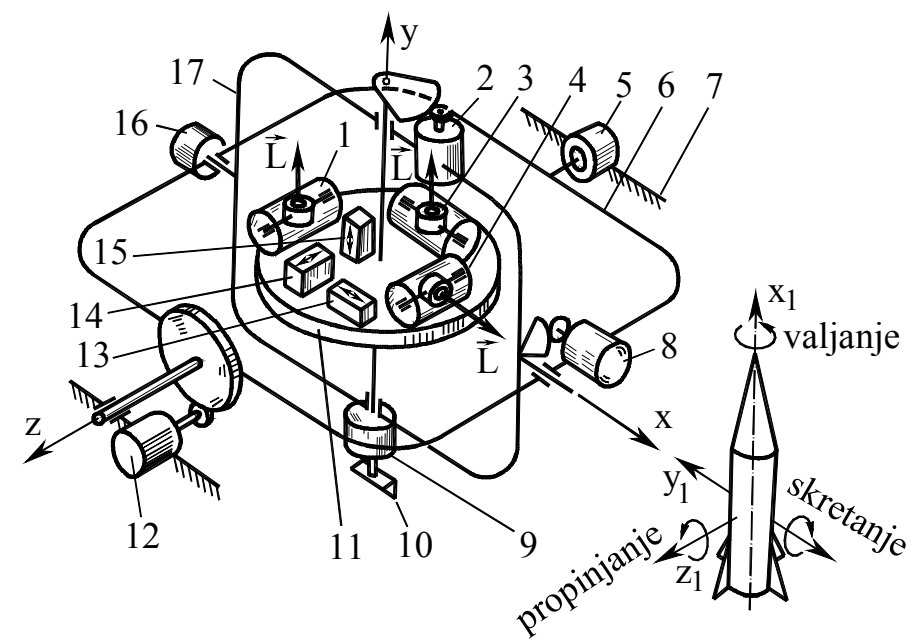

Slika 26 - Šema žirostabilisane platforme

1 - žiroblok ose $x$; 2 - motor za stabilizaciju; 3 - žiroblok ose $z$; 4 - žiroblok ose $y$; 5 - davač komande propinjanja; 6 - spoljni ram; 7 - telo rakete; 8 - motor za stabilizaciju; 9 - davač komande valjanja; 10 - prizma; 11 - ravan stabilizacije; 12 - motor za stabilizaciju;

13 - akcelerometar ose $x ; 14$ - akcelerometar ose $z ; 15$ - akcelerometar ose $y$; 16 - davač komande skretanja; 17 - unutrašnji ram

Žirostabilisana platforma. Žiroskopi mogu da se primene i za stabilizaciju specijalnih platformi. Ove žirostabilisane platforme često se primenjuju kod raketa velikog dometa, kod kojih postoji potreba da se neki uređaji ili instrumenti drže u fiksnom položaju u odnosu na apsolutni koordinatni sistem [8, 9].

$\mathrm{Na}$ sl. 26 prikazana je principijelna šema žirostabilisane platforme rakete „Titan“ sa kardanskom vezom koja se sastoji od dva rama, (6) i (17), utvrđena za oslonac rakete (7). Na platformi (11) postavljena su tri akcelerometra, (13), (14) i (15), koji mere linearna ubrzanja rakete po sve tri ose $x, y$ i $z$ i tri žiroskopa (1), (3) i (4). U odnosu na platformu (11) svaki žiroskop ima dva stepena slobode. Ziroskopi su orijentisani na platformi tako da njihova glavna osa i osa unutrašnjeg rama budu upravne na odgovarajuću osu stabilizacije.

Svaki žiroskop ima davač ugla precesije koji je preko pojačivača spojen sa motorom stabilizacije. Žiroskop (1) i motor (2) stabilišu paltformu u odnosu na osu $x-x$ (osa valjanja), žiroskop (3) i motor (12) - u odnosu na osu $z-z$ (osa propinjanja) i žiroskop (4) sa motorom (2) - u odnosu na osu $y-y$ (osa skretanja).

Razmatra se stabilizacija platforme oko ose y. Ako na platformu (11) deluje moment poremećaja koji teži da je otkloni od zadatog pravca, dejstvo se prenosi na žiroskop (4) i izaziva precesiju. Usled zaokreta rotora za neki ugao, sa davača ugla precesije postavljenog na toj osi skinuće se signal koji preko pojačivača odlazi na motor za stabilizaciju (2). Ovaj motor prenosi na platformu moment koji je suprotan momentu poremećaja i platforma se usled toga neće zaokrenuti oko ose y nego će zadržati svoju prvobitnu orijentaciju. 
Analogno se vrši stabilizacija platforme i za ostale dve ose.

Tako žirostabilisana platforma zadržava stabilno svoj početni položaj (u momentu lansiranja) u toku čitavog leta rakete.

\section{Dalji razvoj žiroskopa}

Radi male pouzdanosti rada zbog, uglavnom, velikog broja obrtnih delova elektromehaničkog žiroskopa, u periodu 1970-1980. godine intenzivno se koriste „suvi“ (dry) ili dinamički podešeni žiroskop DTG (DTG - Dinamically Tuned Gyro), čiji se princip rada zasniva na Hukovom (engl. Hooke) zglobu, jednostavnije je konstrukcije, a ima i manje delova koji se obrću [2, 6, 10].

Sredinom sedamdesetih godina prošlog veka engleska škola razvoja žiroskopa na čelu sa naučnikom Vurdesom intenzivno radi na razvoju piezo-žiroskopa. Telo žiroskopa je izrađeno u obliku diska, a materijal je litijum-niobat ili olovo-cinkonat-titanat. Ovaj tip žiroskopa postigao je linearnost signala od $0,1 \%$, veliku pouzdanost u radu, jeftin je, malih dimenzija, ali je faktor skale bio temperaturno zavisan.

Nakon tridesetogodišnjeg razvoja, početkom 1980. godine, koriste se laserski žiroskopi, čiji se princip rada zasniva na efektu Sagnaca. Naime, svetlosni zrak koji stvara laser deli se na dva dela: jedan, koji se kreće u smeru kazaljke na satu i drugi - suprotno kretanju kazaljki na satu. Zavisno od uglovne brzine vreme dolaska tih svetlosnih zraka u detektor nije isto, tako da je fazna (vremenska) razlika u dolasku tih svetlosnih zraka proporcionalna uglovnoj brzini. Osnovna prednost im je što nemaju pokretne delove, a mana što ne mogu da izmere veoma male uglovne brzine zbog lock-in efekta. Intenzivno se radi na eliminisanju lock-in efekta, ali to usložava njihovu konstrukciju, a povećava i cenu.

Zato su se 1995. godine pojavili komercijalni fiber-optički žiroskopi FOG (FOG - Fiber Optic Gyro), koji takođe koriste efekat Sagnaca, ali kao medijum za prostiranje svetlosti koriste fiber-optička vlakna.

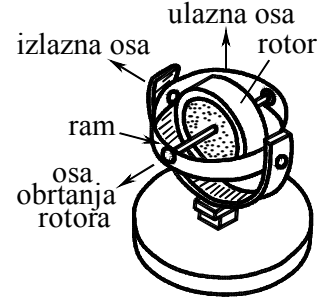

Slika 27 - Mehanički brzinski žiroskop sa jednim stepenom slobode

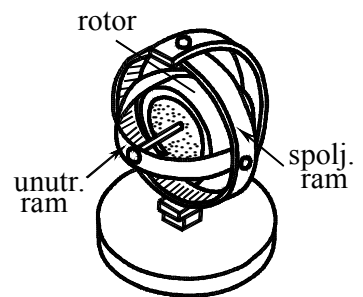

Slika 28 - Mehanički brzinski žiroskop sa dva stepena slobode

$U$ isto vreme, nakon dugog perioda usavršavanja, pojavljuju se i silicijumski „vibrirajući“ $\mu$ - žiroskopi koji rade na principu vibracije viljuške od silicijuma, a 1990. godine firma Northrop lansira prvi precizan $\mu$-optički žiroskop MOG (MOG - Micro Optic Gyro), koji takođe koristi efekat Sagnaca. 
Svaki od navedenih tipova žiroskopa ima određene prednosti, ali i nedostatke. Neki su izrazito malih dimenzija i jeftini, ali zato nedovoljno precizni, dok su drugi veći i skuplji, ali tačnije mere uglovnu brzinu. Od važnosti objekta zavisi i tačnost žiroskopa koji se na njega ugrađuju. Međutim, nekad veoma važnu ulogu imaju: masa, dimenzija i pouzdanost rada žiroskopa, pa se često mora tražiti kompromis.

\section{Zaključak}

Žiroskopski moment, odnosno žiroskopski efekt, javlja se uvek kada se menja pravac obrtne ose žiroskopa. Ako se ta promena brže vrši žiroskopski pritisci u ležištima mogu višestruko da nadmaše vrednost statičkih pritisaka, pa se njihov uticaj mora uzeti u obzir pri proračunu ležišta.

Kod žiroskopa sa dva stepena slobode osa žiroskopa nema osobinu protivdejstva, već se usled promene njenog pravca javlja žiroskopski efekt.

Žiroskopi su našli veliku primenu u tehnici, npr. žiroskopski kompas i drugi žiroskopski navigacioni pribori. U torpedu se žiroskop koristi da bi se obezbedilo stabilno kretanje po unapred određenoj putanji. Isto tako, žiroskop služi da bi se umanjilo ljuljanje broda, zatim kao stabilizator kod jednošinskih vozila gde se koriste žiroskopi sa dva i tri stepena. Da bi se obezbedila stabilna putanja granate, u cevi oruđa urezani su zavojni žlebovi i kada granata napusti cev dobija veliku ugaonu brzinu obrtanja oko svoje ose materijalne simetrije, pa se na taj način obezbeđuje žiroskopska stabilnost granate.

\section{Literatura}

[1] Bodner, V. А.: Приборы первичной информации, Машиностроение, Москва, 1981.

[2] Myers, T. Charles: Guided Missiles - operations, design and theory, McGraw - Hill book company, INC. New York - Toronto London, 1958.

[3] Đurković, P. Vlado: Tehnička mehanika 2., Sektor za školstvo, obuku, naučnu i izdavačku delatnost, Vojnotehnička akademija Vojske Jugoslavije, Beograd, 2000.

[4] Đurić, Slavko: Mehanika III i IV - dinamika i teorija oscilacija, Mašinski fakultet Univerziteta u Beogradu, Beograd, 1976.

[5] Rusov, Lazar: Mehanika - dinamika, Naučna knjiga, Beograd, 1984.

[6] Janićijević, Slobodan: Vazduhoplovni instrumenti visinska i letačka oprema, Vojnoizdavački zavod, Beograd, 2006.

[7] Jovović, Žarko: Projektiranje laboratorijskih vježbi iz predmeta tehnička mahanika - Koriolisova sila i žiroskopski efekti, Mornarički školski centar, Split, 1981.

[8] Назаров, Б. И.: Гироскоп на ракете, Машиностроение, Москва, 1965.

[9] Miljković, Dragiša: Osnovi raketnog naoružanja artiljerije, Vojnoizdavački zavod, Beograd, 1982.

[10] Stanojlović, Spasoje: Konstrukcija i oprema vazduhoplova, Vojnoizdavački i novinski centar, Beograd, 1992. 